\title{
Sejarah Dan Tradisi Desa Selang Kecamatan Kebumen Kabupaten Kebumen Jawa Tengah
}

\author{
Siti Anisatun Nafi’ah \\ Program Studi PGMI, STAINU Purworejo
}

\begin{abstract}
Abstrak
Desa Selang merupakan salah satu desa yang berada di wilayah Kecamatan Kebumen Kabupaten Kebumen Provinsi Jawa Tengah. Desa Selang berbeda dengan desa lain dari sisi tradisi dan terbentuknya desa Selang. Desa Selang memiliki tradisi Pasar Senggol. Banyak dari masyarakat desa lain berkunjung ke Pasar Senggol. Pada masa kini banyak penduduk desa Selang yang tidak memahami terbentuknya desa Selang. Penelitian ini bertujuan untuk memahami sejarah terbentuknya Desa Selang dan beberapa tradisi yang terdapat di Desa Selang, sehingga sejarah lokal yang ada di negara Indonesia tidak terlupakan dari sejarahnya. Metode yang digunakan dalam penelitian ini pertama, heuristik dengan cara mengumpulkan dokumen dan wawancara. Kedua, verifikasi yaitu mengkritisi sumber internal dan eksternal. Ketiga, interpretasi yaitu menganalisis sumber yang kemudian dianalisis dan disintesiskan. Keempat, historiografi adalah pemaparan atau hasil penelitian yang dilakukan. Hasil penelitian menunjukkan bahwa nama Desa Selang sebelumnya adalah Klegen Kilang. Nama Selang berasal dari kata nyelong, yang artinya dalam bahasa Kebumen adalah hilang. Hilang memiliki filosofi sendiri, mengingat-ingat kejadian Raden Ngabehi Karamaleksana menyelongkan Kerta Menggala yang kemudian diambil menantu oleh Raden Ngabehi Kramaleksana. Tradisi yang terdapat di Desa Selang yaitu Pasar Senggol (Pasar Warungan) dan Ziarah ke makam menjelang bulan Ramadhan.
\end{abstract}

Kata Kunci: Sejarah, Tradisi, Desa Selang

\section{Pendahuluan}

Desa Selang merupakan salah satu desa yang cukup strategis di Kabupaten Kebumen. Desa ini berada di pinggiran kota Kebumen, selain itu akses untuk menuju kota Kebumen cukuplah mudah dan desa ini masuk dalam wilayah Kecamatan Kebumen. Batas sebelah utara desa Selang adalah Desa kembaran ,sebelah timur berbatasan dengan desa Kalirejo, sebelah Selatan berbatasan dengan Depokrejo dan sebelah barat berbatasan dengan Panjer.

Desa ini merupakan desa yang subur. Topografi Desa Selang memiliki banyak sawah, perkebunan, dan pasar yang cukup terkenal di Kabupaten
Kebumen. Desa ini mempunyai lapangan yang cukup luas yang sering digunakan warganya untuk melakukan berbagai pertandingan dan juga digunakan untuk berbagai festival. Desa ini dibagi menjadi 10 RW, dan masing-masing RW mempunyai nama-nama dukuh masingmasing yang di antaranya adalah Robahan Selang, Pekisen, Sipitik, dan lain-lain.

Di Desa Selang banyak kegiatan yang sering di adakan seperti Maulid Nabi Muhammad saw, acara memperingati hari kemerdekaan Indonesia, Muharram, dan lain-lain. Di setiap dukuh masing-masing generasi mempunyai perkumpulan sendiri-sendiri seperti bapak-bapak tergabung dalam kelompok Lapanan, ibu- 
ibu masuk dalam kelompok PKK dan remaja masuk dalam kelompok Karang Taruna. Desa Selang mempunyai tradisi yang unik yang tentunya berbeda dengan tradisi-tradisi yang ada di desa lainya yaitu pasar Senggol yang kebetulan tradisi tersebut hanya ada di Desa Selang tidak ada di desa lain khususnya di Kabupaten Kebumen.

Desa Selang merupakan desa yang cukup unik dalam sejarahnya. Banyak orang yang mengenal desa ini tapi mereka tidak begitu memahami bagaimana sejarah desa ini terbentuk, begitu pula orangorang yang tinggal di desa ini. Oleh karena itu peneliti ingin mengkaji bagaimana sejarah desa Selang terbentuk dan tradisi yang ada di Desa Selang.

Berdasarkan latar belakang yang telah diuraikan di atas, maka untuk mewujudkan penulisan ini. Penulis memberikan batasan dan rumusan masalah sebagai berikut. Penelitian ini diawali mulai terbentuknya desa Selang pada masa raja Mataram sampai desa ini dikenal oleh masyarakat Kebumen. Penelitian ini akan difokuskan pada asal usul Desa Selang dan tradisi-tradisi yang dilaksanakan di Desa Selang.

Dalam suatu penelitian tentu terkandung suatu tujuan yang akan dicapai, maka sesuai dengan judul yang telah dikemukakan di atas dan berdasarkan pada rumusan masalah yang telah dijelaskan maka tujuan pokok dari penelitian ini adalah 1). mengungkap filosofi desa Selang, 2). mengetahui tokohtokoh pertama yang mendirikan Desa Selang, dan 3). Mengetahui tradisi-tradisi Desa Selang. Adapun kegunaan penelitian ini dimaksudkan 1). sebagai sumber referensi yang ada di Desa Selang, dan 2). menambah pengetahuan bagi pembaca.

\section{Tinjauan Pustaka}

Setiap bangsa atau suku bangsa memiliki kebudayaan sendiri-sendiri yang berbeda dengan kebudayaan lain atau suku bangsa lain. Sama halnya dengan suku Jawa, yang memiliki kebudayaan yang khas. Dalam penelitian ini ada beberapa buku yang mendukung dalam penelitian ini.

1. Kumpulan tulisan Musa dengan judul Suara Dari Masa ke Silam: sejarah lisan bacaan-bacaan pilihan diterbitkan tahun 2011 di Yogyakarta oleh Fakultas Adab dan Ilmu Budaya UIN Sunan Kalijaga. Buku ini memberikan informasi pentingnya penggunaan metode sejarah lisan dalam mengungkapkan sejarah tokoh. Di dalamnya terdapat tulisan Kuntowijoyo, Bambang Pranowo, Koentjaraningrat dan lainnya yang menaruh perhatian terhadap penggunaan metode wawancara dalam sejarah lisan. Buku ini merupakan acuan dalam melakukan penelitian ini.

2. Karangan Sugeng Priyadi berjudul Sejarah dan Kebudayaan Kebumen 
(Yogyakarta: Jendela, 2003). Buku ini berisi tentang bagaimana sejarah Kebumen. Selain itu menjelaskan tentang sejarah Desa di Kebumen terbentuk dan menjelaskan keturunan yang ada di Desa Selang.

3. Karya Ravie Ananda berjudul Sarasehan Sejarah dan Budaya Panjer. Buku ini berisi tentang cikal bakal Kebumen terbentuk yang awalnya nama Kabupaten Kebumen dahulu adalah Panjer. Dalam buku ini juga sedikit menjelaskan keberadaan Desa Selang.

4. Karya Ravie Ananda yang berjudul Kebumen dan Jejak-Jejak Merah Putih. Buku ini menjelaskan tentang bagaimana Kebumen terbentuk.

\section{Metode Penelitian}

Metode penelitian yang digunakan oleh peneliti adalah kualitatif. Penelitian kualititatif merupakan penelitian yang identik dengan penelitian sejarah. Penelitian Sejarah merupakan penelaah dokumen serta sumber-sumber lain yang berisi informasi mengenai masa lampau dan dilaksanakan secara sistematis (suharsimi arikunto, 2013: 252). Demi mancapai pemahaman sejarah, maka penelitian ini menggunakan empat tahap metode sejarah yaitu:

\section{Heuristik}

Heuristik merupakan pengumpulan sumber-sumber. Pemilihan sumber-sumber didasarkan atas sumber primer dan sekunder. Penelitian ini dilaksanakan dengan cara pengumpulan data primer dan sekunder dengan beberapa cara:

\section{a. Wawancara}

Wawancara merupakan pertemuan dua orang untuk bertukar informasi dan ide melalui tanya jawab sehingga dapat dikonstruksikan makna dalam suatu topik tertentu. Wawancara yang akan dilakukan adalah wawancara terstruktur dan wawancara tak terstruktur (Sugiyono, 2009: 73-74). Wawancara ini merupakan data primer. Peneliti melakukan wawancara dengan sesepuh yang ada di Desa Selang yaitu (1). Haji Sukardi sekarang menjabat menjadi sebagai seorang kyai yang ada di Desa Selang dan (2). M Muslikhudin, merupakan mantan sekertaris, sekaligus guru agama yang di SD N 3 Selang.

\section{b. Dokumentasi}

Dokumen berupa bahan tertulis atau bahan cetakan. Dokumen merupakan sesuatu yang paling umum digunakan sebagai sumber sejarah. Bahan-bahan ini dapat berupa buku harian, rekaman resmi, testimoni, memorandum, buku tahunan, surat kabar, majalah arsip, dan sebagainya. Pada penelitian ini penulis memperoleh arsip sejarah Desa Selang, peta zaman kolonial, trah Desa Selang.

\section{Kritik Sumber (Verifikasi)}

Setelah data-data terkumpul, maka tahap selanjutnya adalah melakukan 
kritik terhadap sumber. Kritik ini meliputi dua aspek, yaitu kritik sumber internal dan eksternal. Kritik internal adalah mengkritisi isi sumber untuk melihat kredibilitas atau kesahihan arsip. Sedangkan kritik eksternal adalah mengkritisi sumber dari sisi luarnya (fisik) sehingga data tersebut diketahui otentiknya.

\section{Interpretasi}

Penelitian sejarah adalah penelitian yang mengandalkan pada kemampuan pelakunya dalam mengadakan interpretasi terhadap sumber yang dianalisis. Setelah kritik intern dan ekstern dilakukan, maka langkah selanjutnya adalah interpretasi atau penafsiran. Hal yang dilakukan dalam tahap ini adalah menganalisis. Berdasarkan sumber primer dan sekunder tentang asal usul Desa Selang, kemudian dianalisis dan sintesis.

\section{Historiografi}

Tahap akhir dari proses penelitian ini adalah penulisan sejarah atau historiografi. Historiografi di sini merupakan cara penulisan pemaparan atau pelaporan hasil penelitian sejarah yang dilakukan (Dudung Abdurahman: 16). Penulisan ini dilakukan secara deskriptif analisis dan berdasarkan sistematika yang telah ditetapkan dalam rencana penelitian. Pada tahap ini, proses penyajian akan disampaikan dengan baik, dalam sistematika juga dalam pembahasannya.

\section{Hasil Dan Pembahasan}

\section{A. Asal Mula Desa Selang}

Asal mula penamaan Desa Selang ada beberapa versi yang peneliti temukan. Menurut Arsip Sejarah/Riwayat Desa Selang ditemukan bahwa Desa Selang ini berasal dari kata selong. Kata selong jika dilihat dalam bahasa jawa adalah nyelong. Nyelong menurut masyarakat Desa Selang artinya Hilang. Hilang dalam hal ini memiliki filosofi dan sejarah sendiri untuk masyarakat Desa Selang. Desa Selang sebelumnya bernama klegen kilang. Klegen Kilang merupakan pemberian nama dari raja Amangkurat.

Seorang bernama Kerta Menggala putra dari Demang Gesikan. Pada suatu hari akan pergi ke Kartasura untuk membayar upeti kepada rajanya. Setelah sampai di Kedungbener, bertemu dengan utusan dari mbah Raden Ngabehi Kramaleksana. Raden Ngabehi Kertamengala diajak atau diselong oleh utusan Raden Ngabehi Kramaleksana ke rumah untuk diambil menantu oleh Raden Ngabehi Kramaleksana. Untuk mengingatngingat kejadian tersebut desa Klegen Kilang diganti nama menjadi Desa Selang.

Menurut Bapak Muslikhudin dan Sukardi pada suatu ketika pusaka mataram ada yang hilang maka raja Mataram mengutus seorang abdi yang bernama Kramayuda untuk mencarinya. Karena Karamayuda lama tidak kembali ke kerajaan Mataram maka dinyatakan hilang 
oleh raja Amangkurat waktu itu. Padahal Kramayuda telah menemukan pusaka itu di rumah Tumenggung Kertinegara yang sekarang masuk dalam desa Bandungsruni, kemudian Kramayuda menyamar untuk menjadi seorang abdi dalem karena Kramayuda seorang yang patuh dan tunduk terhadap aturan-aturan serta keluhuran budinya maka kemudian Kramayuda dijadikan menantu oleh Kertanegara.

Atas jasanya Kramayuda diangkat menjadi demang, kemudian Kramayuda mempunyai anak yang bernama Raden Ngabehi Kramaleksana. Raden Ngabehi Kramaleksana ini menjadi seorang demang yang ada di Desa Selang yang untuk pertama kalinya, Raden Ngabehi Kramaleksana ini mempunyai dua empu yang membantu dalam pemerintahanya yang bernama Nur Jaiman dan Nur Sulaiman. Karena bantuan mereka pemerintahan yang ada di Desa Selang menjadi stabil dan terkenal di antara kademangan yang lain.

Penulis kemudian menelusuri buku yang berjudul sejarah dan Kebudayaan Kebumen yang ditulis oleh Sugeng Priyadi dalam buku tersebut terdapat serat sruni. Pada tulisan tersebut sedikit membahas tentang Desa Selang sebagai berikut. Pada suatu ketika ada seorang tumenggung yang bernama Kertinegara. Tumenggung Kertinegara terkenal sakti. Tumenggung Kertinegara memutuskan untuk membrontak pada raja Amangkurat 1. Raja
Amangkurat juga didukung oleh para tumenggung mantri dan demang. yang ada di sekitar Sruni serta Lurah Ki Sutamenggala. Di samping itu, ada riwayat yang menyatakan bahwa barang siapa yang memiliki pusaka Kanjeng Kiai Jabardas, maka telah memperoleh wahyu keratin. Oleh karena itu, Tumenggung Kertinegara memerintahkan kemenakannya untuk mencuri pusaka tersebut di Keraton Mataram.

Ki Trunayuda mengabdi sebagai abdi dalem yang sangat dikasihi oleh Sunan Amangkurat. Raja berharap akan dapat mengungkap maksud Tumenggung Sruni yang dikabarkan akan membrontak. Namun, raja tidak menyadari bahwa Ki Trunayuda adalah utusan Tumenggung Sruni untuk mencuri pusaka Kiai Jabardas. Setelah dua tahun akhirnya Ki Trunayuda ini berhasil mencuri pusaka Kiai Jabardas. Akhirnya Ki Kertanegra ini berhasil meluaskan wilayahnya sampai ke Tanah Roma (batas barat), batas utara tanah Ledok (Wanasaba), batas timur Kutawinangun, dan batas selatan Samudra serta Sebelah Roma merupakan Selang seperti ditunjukkan pada gambar 1 .

Banyak para mantri maupun bupati tunduk pada Kertinegara. Kemudian pemberontakan yang dilakukan oleh Kertinegara ini terdengar oleh raja Amangkurat kemudian Amangkurat ini mengutus Kanjeng Gusti Pangeran Adipati, Kanjeng Pangeran Puger dan Pepatih 
Dalem untuk mengatasi pemberontakan yang dilakukan oleh Kertinegara. Kanjeng Gusti Pangeran Adipati bermaksud meminjam pusaka Kangjeng Kiai Jabardas akan tetapi pusaka itu telah hilang dan Prabu pun terkejut lalu ia menduga bahwa yang mencuri pusaka itu adalah abdi dalem yang mendapat utusan dari Ki Kertinegara.

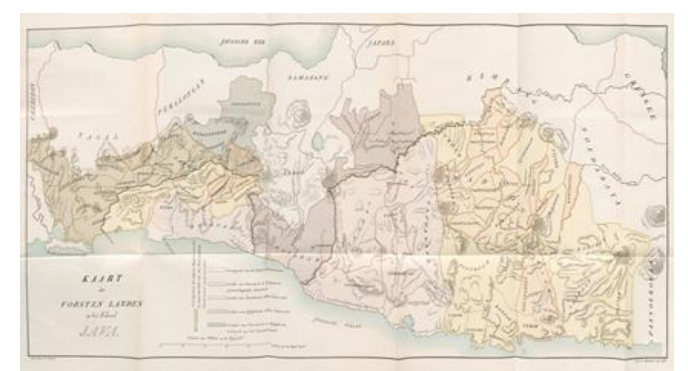

Gambar 1 Peta Desa Selang Pada Abad 18

Amangkurat pun akhirnya mengutus Ki Demang Sutawijaya untuk menjadi mata-mata agar pusaka Kiai Jabardas dapat kembali, Demang Sutawijaya ini lalu dipindahkan menjadi Demang di Kutawinangun. Demang Sutawijaya ini menghadap Ki Kertanegara untuk mengabdi diri, ia mengaku bahwa ia diusir oleh Raja tanpa adanya kesalahan, dan ia mendengar kabar bahwa $\mathrm{Ki}$ Kertinegara adalah seorang pemimpin yang selalu melindungi orang-orang kecil.

Pengabdian ini pun diterima oleh Kertinegara bahkan Ki Demang Sutawijaya ini diangkat menjadi saudaranya. Ki Kertileksana dan Ki Kertasentika mengingatkan ayah mereka agar berhatihati, jangan-jangan Ki Demang Sutawijaya adalah utusan raja Mataram, tetapi kiranya Demang Sutawijaya dapat meyakinkan tumenggung Sruni dan kedua putranya bahwa benar-benar bukan orang Mataram. Setelah tiga tahun mengabdi, Ki Demang Sutawijaya dan istrinya dipanggil untuk menghadap Ki Kertinegara. Ki Kertinegara ini bermaksud untuk mempererat hubungan kekeluargaan dengan Demang Sutawijaya dengan cara menikahkan putri Ki Kertinegara yang bernama Mas Rara Ranti dengan anak lelaki Demang Sutawijaya.

Hal ini membuat Demang Sutawijaya mempunyai kesempatan yang besar untuk mengambil kembali pusaka yang telah dicuri oleh suruhan Kertinegara. Ki Demang Sutawijaya menasehati kepada putranya bahwa dia mempunyai tugas yang besar untuk mengambil pusaka Kiai Jabardas. Seiring berjalanya waktu penyamaran Demang Sutawijaya ini tercium oleh Ki Kertanegara akan tetapi akhirnya sadar bahwa telah berdosa kepada rajanya.

Akhirnya menyerahkan pusaka Kiai Jabardas kepada menantunya yang diteruskan kepada Demang Sutawijaya sebagai utusan raja. Sebelum pusaka Kiai Jabardas diserahkan kepada raja, di ibu kota telah meletus pemberontakan Trunajaya. Dalam peristiwa itu, Sunan (Raja Amangkurat) meloloskan diri dari keratin ke arah barat dengan diiringi Pangeran Adipati Anom dan Pangeran Puger, serta prajurit pilihan. Rombongan Sunan dikejar oleh para pemberontak 
dapat dikalahkan karena takut terhisap sepak terjang prajurit Sruni. Ki Demang Sutawijaya segera menyusul perjalanan Raja Amangkurat yang beristirahat di Banyumas sebab beliau menderita sakit. Ki Demang mengatakan kepada Raja Amangkurat bahwa ia berhasil memperoleh kembali pusaka Kiai Jabardas yang telah hilang. Dan ki Demang Sutawijaya pun menceritakan bahwa ia telah menjadi besan Ki Kertinegara, dan Ki Kertinegara telah menyesali perbuatannya karena telah memberontak kepada Raja Amangkurat.

Penyesalan itu diwujudakan dengan mengirim prajurit kepada Raja Amangkurat untuk berjaga-jaga di Semawung. Demang Sutawijaya mengusulkan kepada raja agar dosa $\mathrm{Ki}$ Kertinegara diampuni. Raja Amangkurat sangat puas mendengar penuturan Demang Sutawijaya, lebih-lebih pusaka Kiai Jabardas dapat dikembalikan kepada Pangeran Adipati Anom. Akhirnya Ki Kertinegara diampuni segala dosanya oleh Raja Amangkurat. Dan memutuskan daerah yang dikuasai oleh Ki Kertinegara menjadi wedana bupati dengan memakai gelar Raden Tumenggung.

Setelah semua keputusan raja diterima, Demang Sutawijaya kembali ke Kutawinangun, tetapi ia membatalkan diri karena sakitnya Raja Amangkurat. Tidak lama kemudian, Raja Amangkurat meninggal di wilayah Banyumas dan dikuburkan di Tegalarum. Sepeninggal Raja
Amangkurat, Demang Sutawijaya pulang ke Kutawinangun dan menceritkan semua keputusan Sunan kepada Tumenggung Kertinegara. Tumenggung Kertinegara sangat gembira atas pengampunan dan anugrah jabatan dari raja Amangkurat. Jabatan Kertinegara setara dengan kedudukan Bupati banyumas, Raden Tumenggung Yudanegara.

Pemberontakan Trunajaya telah dipadamkan dan Pangeran Adipati Anom menjadi raja dengan gelar Susuhunan Amangkurat II. Surat kakancingan bagi Raden Tumenggung Kertinegara diserahkan kepada Amangkurat II sebagai kepanjangan ayahnya. Penyerahan kekancingan itu diikuti dengan acara perkawinan putri Tumenggung Kertinegara yang bernama Mas Rara Rinten dengan Ki Kramaleksana, putra Ki Kramayuda, penduduk Sruni.

Berdasarkan hasil wawancara penulis, arsip, dan buku yang ditulis oleh Sugeng Priyadi terdapat perbedaaan. Menurut Bapak Muslikhudin dan Kyai Haji Sukardi, serat Sruni, dan arsip terdapat perbedaan pendapat. Menurut arsip riwayat Desa Selang penamaan Selang karena untuk mengingat-ingat kejadian Raden Ngabehi Karamaleksana menyelongkan Kerta Menggala. Sedangkan menurut Bapak Muslikhudin dan Kyai Haji Sukardi pada waktu itu ada utusan dari Mataram yang bernama Kramayuda untuk mencari pusaka tidak pernah kembali, 
kemudian dinyatakan hilang oleh Raja Mataram dan baru ditemukan di Klegen Kilang. Menurut serat Sruni yang diutus adalah oleh kerajaan Mataram bernama Sutawijaya untuk mencari pusaka Kyai Jabardas, sedangkan Kertinegara mengutus Trunayuda untu mencari Kyai Jabardas.

Menurut penulis dari tiga sumber tersebut, penulis menganggap saling melengkapi. Penulis menganalisis bahwa penamaan Desa Selang lebih kepada untuk mengingat-ingat kejadian Raden Ngabehi Karamaleksana menyelongkan Kerta Menggala. Sebab menurut penulis terjadinya pusaka hilang yaitu Kiai Jabardas merupakan serangkaian peristiwa sebelum terjadinya penamaan Desa Selang.

Pada pembahasan sebelumnya telah disebutkan bahwa Desa Selang sebelumnya bernama Klegen Kilang yang diberikan oleh raja Amangkurat. Penamaan Klegen Kilang terkait dengan peristiwa hilangnya pusaka mataram, dimana Kramayuda untuk mencari pusaka tidak pernah kembali, kemudian dinyatakan hilang oleh Raja Mataram dan baru ditemukan di Klegen Kilang karena diambil menantu oleh Kertinegara.

Pada akhirnya Kramayuda diangkat menjadi seorang demang di Klegen Kilang. Kramayuda kemudian memiliki anak bernama Radeng Ngabehi Kramaleksana. Raden Ngabehi Kramaleksana kemudian menjadi demang di Selang. Versi Serat Sruni menyatakan bahwa yang mencuri pusaka mataram adalah Trunayuda. Trunayuda merupakan utusan dari Kertanegara. Raja Amangkurat mengutus Demang Sutwaijaya untuk mencari pusaka. Pada akhirnya Sutawijaya dijodohkan dengan anaknya yaitu Mas Rara Ranti. Selanjutnya Raja Amangkurat membuat surat kakancingan bagi Raden Tumenggung Kertinegara diserahkan kepada Amangkurat II sebagai kepanjangan ayahnya.

Penyerahan kekancingan itu diikuti dengan acara perkawinan putri Tumenggung Kertinegara yang bernama Mas Rara Rinten dengan Ki Kramaleksana, putra Ki Kramayuda, penduduk Sruni. Menurut Bapak Muslikhudin dan Sukardi bahwa Desa Selang pertama kali dipimpin oleh Kramaleksana yang merupakan anak keturunan dari Prabu Brawidjaya Ke IV di Majapahit (lihat gambar 2 dan 3).



Gambar 2 Asal Usul Trah Kramaleksana Brawidjaya V di Majapahit sampai Graat IV (Sumber: Panitia Makam R.Ng. Kramaleksana Tahun 1984/1985) 


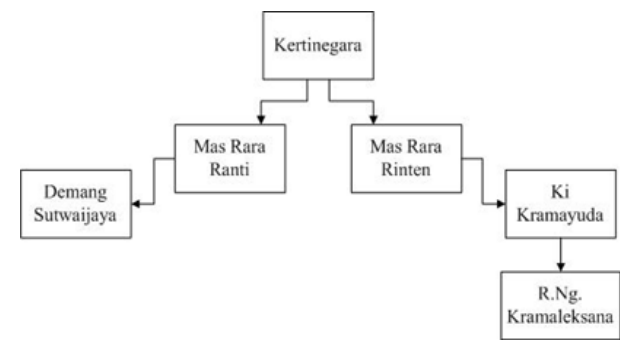

Gambar 3 Asal Usul Keturunan Kramaleksana.

\section{B. Tradisi di Desa Selang}

\section{Pasar Senggol}

Menurut Bapak Muslikhudin dan Bapak Kyai Haji Sukardi bahwa pada zaman Mataram para demang memiliki kewajiban untuk membayar upeti ke Mataram. Para demang ketika akan membayar upeti di tengah perjalanan sering terjadi perampokan. Sehingga para demang bermusyawarah, agar upeti tersebut sampai ke Mataram (Kartasura). Dengan pertemuan para demang sepakat untuk membayar upeti bersama-sama ke Mataram sehingga upeti itu sampai ke Kerajaan Mataram. Maka para demang memutuskan untuk singgah bersama-sama di bawah sebuah pohon pelem yang besar.

Pembayaran upeti dilakukan dalam satu tahun dua kali yaitu pada Bulan Maulud dan Syawal menjelang hari raya Idul Fitri. Pada sore hari menjelang tanggal 12 Maulud dan tanggal 1 Syawal para demang berkumpul di tempat tersebut yaitu Warung Pelem. Pada waktu itu banyak orang-orang yang di sekitarnya yang ingin melihat para demang. Para demang sambil istirahat dan menginap kemudian muncul Warung Pelem. Disebut warung pelem karena warung/pasar itu berada di bawah pohon pelem dan secara kebetulan banyak yang berjualan buah pelem. Kejadian seperti ini seolah-olah menjadi sebuah tradisi. Tiap Bulan Maulud dan Syawal masyarakat sekitarnya berbondong-bondong mengunjungi pasar sore atau pasar warung Pelem.

Dari pertemuan tersebut sampai sekarang masih dikenang masyarakat Desa Selang dan sekitarnya, mereka selalu memperingati setiap tanggal 12 Maulud dan 1 Syawal. Pada awalnya warung pelem berada di dukuh Adikarso kemudian dipindah ke Desa Selang. Anak-anak sangat senang ketika akan ada pasar warung setiap tanggal tersebut. Bahkan ada nyanyian khusus setiap menjelang tradisi teresbut yaitu suk suk sarungan esuk-esuk pasar warungan.

Artinya suk suk sarungan adalah besok pagi pasar warungan. Ada juga yang menamakan pasar senggol. Masyarakat Desa Selang dan sekitarnya sering berkunjung ke tradisi tersebut. Nama senggol sendiri karena saling besenggolan dengan orang lain. Konon kabarnya menurut paham-paham orang dulu orang yang ikut pasar senggol selalu awet muda dan barang siapa ingin mendapat jodoh maka beli bunga dan untuk mandi. Atas izin Allah agar mendapat jodoh.

\section{Rapat Kerja Guru}

Untuk mengenang jasa Raden Ngabehi Kramaleksana, pemerintah melalui 
Unit Pelaksana Dinas Pendidikan Pemuda dan Olahraga (UPTD Dikpora) Unit Kecamatan Kebumen mendirikan kelompok kerja guru yang terdiri dari Sekolah Dasar Negeri 1 Selang, Sekolah Dasar Negeri 3 Selang, Sekolah Dasar Negeri 1 Kalirejo, Sekolah Dasar negeri 2 Kalirejo, dan Sekolah Dasar Negeri 3 Kalirejo diberi nama gugus kramaleksana.

Setiap hari Sabtu semua kepala sekolah dan guru serta staff bermusyawarah untuk melaksanakan program pemerintah yang berkitan dengan pendidikan seperti memajukan peserta pendidik di Desa Selang.

\section{Ziarah Kubur}

Tak kala juga masyarakat Selang dan sekitarnya setiap bulan sya'ban hari Jum'at ketiga mereka berbondog-bondong berziarah ke makam Kramaleksana untuk mendoakannya atas pengabdian dan jasa Karamaleksana sehingga dapat diterima di sisi Allah swt.

\section{Penutup}

\section{Kesimpulan}

Nama Desa Selang sebelumnya adalah Klegen Kilang. Nama Selang berasal dari kata nyelong, yang artinya dalam bahasa Kebumen adalah hilang. Hilang memiliki filosofi sendiri, mengingat-ingat kejadian Raden Ngabehi Karamaleksana menyelongkan Kerta Menggala yang kemudian diambil menantu oleh Raden Ngabehi Kramaleksana. Tradisi yang terdapat di Desa Selang yaitu Pasar Senggol (Pasar Warungan) dan Ziarah ke makam menjelang bulan Ramadhan.

\section{Daftar Pustaka}

Arsip Sejarah/Riwayat Desa Selang Kecamatan Kebumen Kabupaten Kebumen.

Dudung Abdurahman. 2011. Metodologi Penelitian Sejarah Islam. Yogyakarta: Ombak.

Https://kbbi.web.id/ diakses pada tanggal 14 November 2018.

Imam Muhsin, Zuhrotul Latifah, dan Ali Sodiqin. 2008. Sejarah Islam Lokal. Yogyakarta: Bidang Akademik.

Musa. 2011. Suara dari Masa Silam: Sejarah Lisan Bacaan-bacaan Pilihan, Yogyakarta: Fak. Adab dan Ilmu Budaya UIN Yogyakarta.

Priyadi Sugeng. 2003. Sejarah dan Kebudayaan Kebumen. Yogya: Jendela.

Sugiyono. 2009. Memahami Penelitian Kualitatif. Bandung: Alfabeta.

Suharsimi Arikunto. 2013. Manajemen Penelitian. Jakarta: Rineka Cipta.

Wawancara KH. Sukardi tanggal 6 April 2013 jam 17:00-18:00 di Jalan Kutoarjo No 16 RT 01 RW 01 Selang.

Wawancara Muslikhudin A, Ma. Guru Agama Islam, pada 6 April 2013 jam 13:00-15:00 di Jalan Kutoarjo No 14 Kebumen RT 01 RW 01 Selang Kebumen. 